\title{
Wave surge increases rates of growth and nutrient uptake in the green seaweed Ulva pertusa maintained at low bulk flow velocities
}

\author{
Neill G. Barr, Anne Kloeppel, T. Alwyn V. Rees, Cordula Scherer, Richard B. Taylor*, \\ Anja Wenzel
}

Leigh Marine Laboratory, University of Auckland, PO Box 349, Warkworth, New Zealand

\begin{abstract}
Effects of wave surge on growth and nutrient uptake in the green seaweed Ulva pertusa were measured in small tanks fed natural seawater via a dump bucket that could be either locked in place to deliver water continuously, or set to tip at particular volumes. Rates of bulk water flow through the tanks were low $\left(<13 \mathrm{~mm} \mathrm{~s}^{-1}\right)$, as may be typical of highly sheltered marine and estuarine environments. At the maximum bulk flow rates tested, wave surge increased growth in wet mass 1.6fold. Wave surge increased the rate of ammonium uptake 1.5 -fold over the full range of bulk flow rates tested $\left(0.2\right.$ to $\left.2.9 \mathrm{~mm} \mathrm{~s}^{-1}\right)$. In winter, when light probably limited $U$. pertusa in our outdoor cultures, growth in wet mass was relatively unaffected by wave surge and completely unaffected by the experimental addition of nutrients ( $\mathrm{N}$ and $\mathrm{P}$ ). However, in summer, when ambient nutrients probably limited growth, wave surge increased growth in wet mass at low $\left(0.21 \mathrm{~mm} \mathrm{~s}^{-1}\right)$ and high $\left(4.06 \mathrm{~mm} \mathrm{~s}^{-1}\right)$ bulk flow rates, and nutrients increased growth rates at low but not high bulk flow rates. Together, these results indicate that the effect of wave surge on $U$. pertusa at low bulk flow rates (ca. $<2 \mathrm{~mm}$ $\mathrm{s}^{-1}$ ) is to enhance the seaweed's access to nutrients. However, at higher bulk flow rates wave surge has a different effect, which we speculate is due either to provision of a micronutrient or removal of an inhibitory substance from the concentration boundary layer. Our work demonstrates how the lack of small-scale water movement in sheltered habitats can constrain seaweed growth.
\end{abstract}

KEY WORDS: Algae $\cdot$ Diffusion $\cdot$ Growth $\cdot$ Nutrient uptake $\cdot$ Wave surge

Resale or republication not permitted without written consent of the publisher

\section{INTRODUCTION}

Water movement has a profound influence on the physiology and ecology of seaweeds. Moderate levels of water movement benefit most seaweeds by making light available to basal fronds, keeping surfaces free of sediments, hindering grazers and replenishing nutrients (Leigh et al. 1987, Hurd 2000). The negative effects of extremely violent water movement are clearly seen in the detachment or destruction of seaweeds (Lobban \& Harrison 1997), but the negative effects of low water movement are less obvious. Very low levels of water movement $\left(<0.02\right.$ to $\left.0.2 \mathrm{~m} \mathrm{~s}^{-1}\right)$, albeit rarely studied (Parker 1981， 1982, Wheeler 1982, Hurd et al. 1996), can limit growth by restrict- ing the supply of macronutrients such as nitrogen and phosphorus (Wheeler 1988, Hurd 2000). This restriction in nutrient supply is due to: (1) a diminished input of nutrients to the larger body of water surrounding the seaweed and (2) the formation of a concentration boundary layer (e.g. Nishihara \& Ackerman 2007) through which nutrients must diffuse before reaching uptake sites on the surface of the seaweed. Many seaweeds inhabit environments where there is little water movement over significant periods of time. Common examples of such environments are tidepools, sheltered rocky reefs, the interior of dense kelp forests and sheltered estuaries at slack water (Wheeler 1988, Koch 1993, 1994, Pearson et al. 1998). 
When ambient nutrient concentrations are low but demand is high, rates of nutrient uptake by a seaweed are physically limited and increase under elevated bulk concentration and/or a higher rate of delivery to the thallus (thinning of the diffusive boundary layer). However, when nutrients are in excess of demands, uptake becomes biologically limited, and there are also transitional phases in uptake between physical and biological limitation (Sanford \& Crawford 2000). Consequently, in addition to the influence of low nutrient concentration in the medium, uptake of nutrients is affected by both the resupply of nutrients on a broad scale via bulk water flow (Fujita \& Goldman 1985, Larned \& Atkinson 1997) and the effect of smaller scale water movement on thickness of the concentration boundary layer and larger zones of stagnant water in between thalli (Gaylord et al. 1994). A positive effect of small-scale mixing on nutrient uptake, photosynthesis and nitrogen fixation has been reported for a variety of aquatic autotrophs (Carpenter et al. 1991, Williams \& Carpenter 1998, Thomas \& Cornelisen 2003). The importance of small-scale mixing is also recognised in the applied literature, where devices such as dump buckets are commonly recommended for generating wave action in order to increase the nutrient uptake rates and productivities of sessile aquatic organisms (e.g. Craggs et al. 1996, Luckett et al. 1996, Adey \& Loveland 1998). It has been shown that cultured algal turfs supplied with water in intermittent wave surges are substantially more productive than those fed a constant flow of water at the same bulk flow rates (Adey \& Hackney 1989). However, to our knowledge, no study has identified the mechanism(s) by which wave surge increases growth for a particular species of aquatic autotroph.

The first aim of our study was to determine the effect of wave surge on growth of the green seaweed Ulva pertusa Kjellman across a range of bulk flow rates. Ulva is a cosmopolitan genus that is often abundant in wave-sheltered estuaries (Raffaelli et al. 1998) and rockpools (Stephenson \& Stephenson 1972), where its intrinsic capacity for rapid rates of nutrient uptake (Rosenberg \& Ramus 1984) and growth (Littler \& Arnold 1982, Nielsen \& Sand-Jensen 1990) may be constrained by boundary layer effects. The second aim was to identify the mechanism(s) behind the observed effect of wave surge on growth.

\section{MATERIALS AND METHODS}

Collection site. Ulva pertusa were collected from pools in intertidal sandflats at Otumoetai in Tauranga Harbour, north-eastern New Zealand (37³9.68' S, $\left.176^{\circ} 08.46^{\prime} \mathrm{E}\right)$. They were transported to the University of Auckland's Leigh Marine Laboratory (36 $16.21^{\prime} \mathrm{S}$, $174^{\circ} 47.84^{\prime} \mathrm{E}$ ), and held for at least a week prior to experiments in an outdoor tray fed by flow-through seawater drawn from the adjacent seashore. This tray was covered in shadecloth that excluded $50 \%$ of incident sunlight.

Experimental setup. All experiments were run in polypropylene tubs $0.47 \mathrm{~m}$ long $\times 0.18 \mathrm{~m}$ wide $\times 0.13 \mathrm{~m}$ high, each containing $\sim 4.21$ of water. Each tub contained a dump bucket made of PVC guttering into which seawater was fed (Fig. 1). Once the water in the dump bucket reached a certain level (maximum of $1.21)$, the bucket overbalanced and tipped its contents into the tub, thus generating a periodic wave surge. Dump size and frequency were adjusted by altering the tipping point using an adjustable set screw (see Fig. 1). For treatments without wave surge, the dump bucket was locked in a downward position. The rate of seawater input was varied using nozzles of differing diameters. The flow rate (in $1 \mathrm{~min}^{-1}$ ) was measured at least once for each tub during every experiment and converted to a bulk flow velocity along the tub $\left(\mathrm{mm} \mathrm{s}^{-1}\right)$ by factoring in tub length and volume. For instance, since the tubs were $0.47 \mathrm{~m}$ long and held $\sim 4.2 \mathrm{l}$ of water, seawater entering a tub at $4.21 \mathrm{~min}^{-1}$ would take 1 min to travel the length of the tub, and thus have a bulk flow rate of $0.47 \mathrm{~m} \mathrm{~min}^{-1}=7.83 \mathrm{~mm} \mathrm{~s}^{-1}$. For a given rate of seawater input, the long-term mean bulk flow velocity was the same whether dump buckets were locked in place or tipping, although the variability of flow obviously differed (i.e. was constant when the dump bucket was locked in place and pulsed when the dump bucket was tipping).

Measurements of seaweed growth were made in an unshaded, northward-facing outdoor system at the University of Auckland's Leigh Marine Laboratory. Flow-through seawater filtered to $\sim 200 \mu \mathrm{m}$ was supplied to each of 16 tubs from the laboratory's system (intake $\sim 20 \mathrm{~m}$ offshore, $\sim 1 \mathrm{~m}$ below mean low water spring), i.e. the same source of seawater fed to sea-

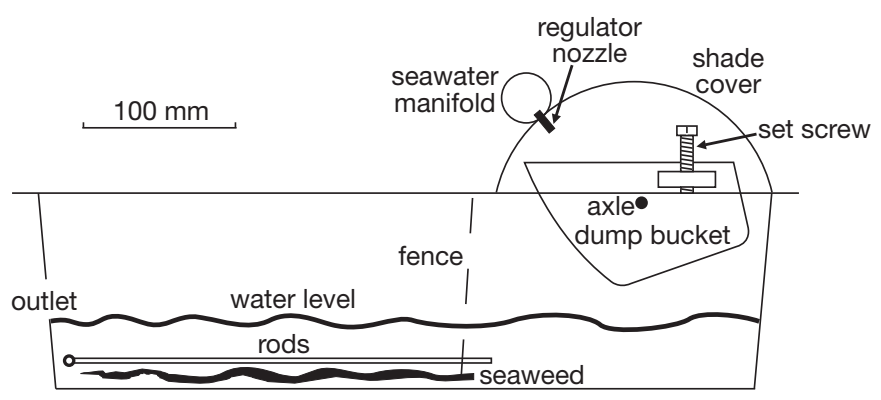

Fig. 1. Experimental setup used to measure the effects of wave surge on seaweed growth and nutrient uptake. Flowthrough natural seawater was fed into each replicate container via a single 201 header tank and manifold 
weeds in the holding tank. A single 201 header tank was used to keep the seawater supply to individual tubs constant over time. All 16 tubs were located within a large tray, into which their seawater discharged through a horizontal slot $50 \mathrm{~mm}$ above the bottom of the tub at the opposite end from the dump bucket. A standpipe in the tray kept the water level at $25 \mathrm{~mm}$ above the bottom of each tub, which enabled the tray to function as a constant-temperature waterbath and thus prevented water in low-flow treatment tubs from heating up in the sun. To stop the Ulva pertusa from being washed out of the tub, floating to the surface, or bunching up near the outlet, plants were spread out in a flat sheet and kept in place by pinning them loosely beneath a row of 6 clear $3 \mathrm{~mm}$ plastic rods and at one end under a vertical fence by the dump bucket (13 mm mesh). During experiments, U. pertusa were weighed $( \pm 0.01 \mathrm{~g})$ after surface drying with a salad spinner (6 pulls of the cord), initially at 0,1 , and then every $2 \mathrm{~d}$ thereafter, for a total of 7 to $10 \mathrm{~d}$. The starting mass was $\sim 3 \mathrm{~g}$. The 0 to $1 \mathrm{~d}$ data were usually discarded as the plants took a day to acclimate, as were data showing limitation due to self-shading, etc. (i.e. where plots of relative growth rate over time showed a sudden decline towards the end of a run). In each experiment, data for the same range of days were used for all replicates. We discarded data for plants that sporulated heavily during experiments. Data were expressed as daily relative growth rates, calculated as:

Relative growth $=\ln ($ final mass $/$ initial mass $) /$ time

where mass is in $\mathrm{g}$ wet wt and time is in $\mathrm{d}$.

Data on ambient seawater nutrient levels were taken from the Leigh Marine Laboratory's weekly record (B. Dobson unpubl. data). Ammonium was determined as described by Koroleff (1983a) and nitrite as in Parsons et al. (1984). Nitrate was reduced to nitrite by passing $20 \mathrm{ml}$ of seawater sample through a cadmium column, and then determined using the method described by Parsons et al. (1984). Phosphate was determined as described by Koroleff (1983b). Data on solar radiation and seawater temperature were taken from the Leigh Marine Laboratory's daily record (J. Evans unpubl. data). Daily solar radiation is measured at the Leigh Marine Laboratory using a Kipp \& Zonen pyranometer, and seawater surface temperature is taken $\sim 100 \mathrm{~m}$ from the intake of the laboratory's seawater system. We did not measure salinity, but 24 yr of daily measurements at the Leigh Marine Laboratory (at the same site as for seawater surface temperature) revealed little variation from a mean of $\sim 35.2 \%$.

Effect of wave surge on growth at varying bulk flow rates. The effect of wave surge on growth of Ulva pertusa at varying bulk flow rates was measured in an orthogonal experiment with the factors of wave surge (absent/present using dump buckets tipping at a volume of $0.75 \mathrm{l})$ and rate of seawater input $(0.08,0.15$, $0.42,0.51,0.93,2.76,4.43$ and $6.961 \mathrm{~min}^{-1}$, equivalent to average horizontal flow velocities through each tub ranging from $\sim 0.14$ to $12.98 \mathrm{~mm} \mathrm{~s}^{-1}$ ). We could only accommodate 1 replicate at a time in our 16 tubs, so we ran the entire experiment 3 times from 8 March to 2 April 2004, with each experiment running for 6 to $7 \mathrm{~d}$. During the experiments, mean ambient seawater total inorganic nitrogen (TIN) and phosphate concentrations were 2.1 to $2.2 \mu \mathrm{M}$ and 0.33 to $0.39 \mu \mathrm{M}$, respectively. Solar radiation averaged 16.8 $\mathrm{MJ} \mathrm{m}^{-2} \mathrm{~d}^{-1}$ and seawater temperature averaged $18.7^{\circ} \mathrm{C}$.

Effect of varying levels of wave surge on growth at a constant bulk flow rate. At a given bulk flow rate the tipping position of the dump buckets could be altered to create a gradient of wave action ranging from small and frequent to large and infrequent (i.e. the frequency of wave events decreased with increasing volume). To determine how this variation in the hydrodynamic regime affected growth, we maintained Ulva pertusa in tubs with dump buckets tipping at volumes of $0,0.25,0.5,0.75$, or $1.0 \mathrm{l}$, with all tubs receiving seawater at $1.21 \mathrm{~min}^{-1}$ (equivalent to an average horizontal flow velocity through each tub of $2.24 \mathrm{~mm} \mathrm{~s}^{-1}$ ) $(\mathrm{n}=3)$. This experiment ran from 22 to 29 October 2005, when ambient seawater TIN and phosphate concentrations averaged 0.8 to $3.3 \mu \mathrm{M}$ and 0.40 to $0.75 \mu \mathrm{M}$, respectively, solar radiation averaged 23.4 $\mathrm{MJ} \mathrm{m}^{-2} \mathrm{~d}^{-1}$ and seawater temperature averaged $16.6^{\circ} \mathrm{C}$.

Effect of wave surge on ammonium uptake. The effect of wave surge on the rate of ammonium uptake by Ulva pertusa was measured at a range of bulk flow rates in a system similar to that pictured in Fig. 1, except that the outlet to the tub was closed, water flow to the dump buckets was recirculated by a small $12 \mathrm{~V}$ DC water pump (maximum flow rate $\sim 1.71 \mathrm{~min}^{-1}$ ) submersed at the opposite end of the tub, and plants were not pinned in place (this was unnecessary due to the lack of an outlet). An orthogonal experiment was run with the factors of wave surge (absent/present using dump buckets tipping at a volume of $0.75 \mathrm{l}$ ) and rate of seawater input $(0.1,0.2,0.4,0.6,0.8,1.0,1.2$, or 1.61 $\mathrm{min}^{-1}$, equivalent to average horizontal flow velocities through each tub of 0.21 to $2.94 \mathrm{~mm} \mathrm{~s}^{-1}$ ) (n=3). Each chamber was filled with 4.51 of seawater to which ammonium chloride was added to a final concentration of $10 \mu \mathrm{M}$ (not including ambient ammonium of $\sim 1.2 \mu \mathrm{M}$ ). After taking a $5 \mathrm{ml}$ seawater sample, a single whole $U$. pertusa plant ( $5 \mathrm{~g}$ wet weight) was added to the tub, and a further $5 \mathrm{ml}$ seawater sample was taken at $30 \mathrm{~min}$. Ammonium concentrations in the seawater samples were determined following Koroleff (1983a). The rate of ammonium uptake for each replicate was calculated as the difference in the quantity of ammo- 
nium in the seawater between 0 and $30 \mathrm{~min}$, divided by the dry weight of the $U$. pertusa (determined after drying for $24 \mathrm{~h}$ at $80^{\circ} \mathrm{C}$ ). In the absence of $U$. pertusa, ammonium concentrations in spiked tubs were relatively constant over $1 \mathrm{~h}$, decreasing by an average of $0.24 \mu \mathrm{M}(\mathrm{SE}=0.27, \mathrm{n}=3$ tubs). Experiments were run between 12:00 and 14:30 h New Zealand standard time from 10 to 14 November 2003, when solar radiation averaged $21.9 \mathrm{MJ} \mathrm{m}^{-2} \mathrm{~d}^{-1}$ and seawater temperature averaged $16.2^{\circ} \mathrm{C}$.

Effect of nutrient addition and wave surge on growth at two bulk flow rates in summer and winter. If wave surge increased growth rates by thinning the concentration boundary layer and thereby increasing the availability of nutrients, we would predict that the effect of adding wave surge and nutrients on growth would be negligible in winter when ambient nutrient levels are high and growth may be light- or temperature-limited, but significant in summer when ambient nutrient levels are low and potentially limiting (Parker 1981, 1982). We therefore measured the growth of Ulva pertusa in response to the following factors in an orthogonal experiment: rate of seawater input $(0.11$ and $2.18 \mathrm{l} \mathrm{min}^{-1}$, equivalent to average horizontal flow velocities through each tub of 0.21 and $4.06 \mathrm{~mm} \mathrm{~s}^{-1}$ ), wave surge (absent/present using dump buckets tipping at a volume of $0.75 \mathrm{l}$ ) and nutrients (ambient/ambient plus $10 \mu \mathrm{M}$ ammonium and $1 \mu \mathrm{M}$ phosphate). Nutrients or distilled water only (control) were continuously added into the dump buckets from stock solutions of ammonium chloride and sodium dihydrogen phosphate using a peristaltic pump. The concentration of the stock solution varied for each replicate, depending on the measured rate of seawater input for that replicate. Seawater nutrient concentrations in each replicate were checked, and the pump rate was adjusted if necessary. A total of 4 replicates was run per treatment, which necessitated running 2 replicates in each of 2 consecutive experimental runs. We ran this experiment in winter (28 June to 8 July 2004 and 23 July to 3 August 2004), when ambient nutrient levels were high (total inorganic nitrogen 3.0 to $6.8 \mu \mathrm{M}$, phosphate 0.37 to $0.50 \mu \mathrm{M}_{i}$ B. Dobson unpubl. data) and light and water temperatures were low (solar radiation averaged $7.8 \mathrm{MJ} \mathrm{m}^{-2} \mathrm{~d}^{-1}$, seawater temperature averaged $14.0^{\circ} \mathrm{C}$ ), and again in summer (24 January to 3 February 2005 and 8 to 18 February 2005), when ambient nutrient levels were low (total inorganic nitrogen 1.5 to $2.1 \mu \mathrm{M}$, phosphate 0.22 to 0.29 $\mu \mathrm{M}$ ) and light and water temperatures were high (solar radiation averaged $21.7 \mathrm{MJ} \mathrm{m}^{-2} \mathrm{~d}^{-1}$, seawater temperature averaged $20.3^{\circ} \mathrm{C}$ ).

Data analysis. Due to the limited number of tubs ( $\mathrm{n}=16$ ), it was necessary to run 2 or 3 consecutive experiments in order to generate the desired number of replicates in all experiments, except for those on the effect of varying levels of wave surge on growth at a constant bulk flow rate. To minimise variance between experimental runs, data were standardised prior to presentation and analysis by equalising the average rate of growth or ammonium uptake across all replicates (in all treatments) for each run. To do this, the value of each replicate within an experimental run was multiplied by the ratio of the average growth rate of all experimental runs to the average value of all replicates for that particular experimental run. Error bars and statistical tests were calculated on the basis of all individual replicates (standardized as described). Regression lines were fitted by ordinary least squares. Treatment effects were examined using 1-way and 3-way ANOVAs. All data met the assumption of homogeneity of variances according to Cochran's test (Cochran 1951). Tukey's honestly significant difference test was used to compare among means.

\section{RESULTS}

In the absence of wave surge, the average rate of relative growth of Ulva pertusa increased slowly with increasing bulk flow rate to a maximum of $0.13 \mathrm{~d}^{-1}$ (Fig. 2). The addition of wave surge had no effect on growth at the lowest common bulk flow rate of $0.14 \mathrm{~mm} \mathrm{~s}^{-1}$ (ratio of growth with wave surge to growth without wave surge $=1.00$ ), but, at higher bulk flow rates, wave surge had an increasingly positive effect, boosting growth 1.6-fold at the maximum common bulk flow rate of $12.31 \mathrm{~mm} \mathrm{~s}^{-1}$. Interestingly, the most rapid rate of increase in the effect of wave surge occurred at low bulk flow rates, with the ratio of growth with wave surge to growth without wave surge increasing from 1.00 to 1.37 once the bulk flow rate reached $1 \mathrm{~mm} \mathrm{~s}^{-1}$.

When the bulk flow rate was kept constant $(2.24 \mathrm{~mm}$ $\mathrm{s}^{-1}$ ), the magnitude and frequency of wave surge had little effect on growth (Fig. 3). In treatments receiving wave surge, relative growth rates of Ulva pertusa averaged 0.20 to $0.22 \mathrm{~d}^{-1}$, regardless whether dump buckets were tipping small volumes frequently $(0.251$ every $11 \mathrm{~s})$ or large volumes infrequently ( 11 every $45 \mathrm{~s})$. $U$. pertusa receiving no wave surge had average relative growth rates of only $0.13 \mathrm{~d}^{-1}$.

Wave surge increased the average rate of ammonium uptake 1.5-fold across the full range of bulk flow rates tested ( 0.2 to $2.9 \mathrm{~mm} \mathrm{~s}^{-1}$ ) (Fig. 4). The shape of the relationship between ammonium uptake rate and bulk flow rate was broadly similar to that for growth (Fig. 2), except that, at low bulk flow rates, wave surge had a larger effect on ammonium uptake than on growth.

During winter, when ambient nutrient levels were relatively high, the addition of the macronutrients 


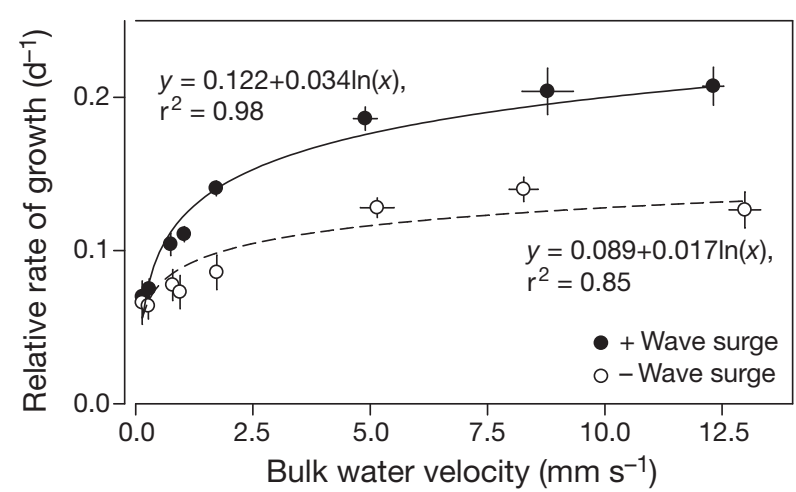

Fig. 2. Ulva pertusa. Effect of wave surge on relative growth rates $\mathrm{d}^{-1}$ (in $\mathrm{g}$ wet weight per day) of specimens maintained at a range of bulk flow rates in outdoor tanks. Symbols represent mean $\pm 1 \mathrm{SE}(\mathrm{n}=3)$. Regression lines were fitted by ordinary least squares

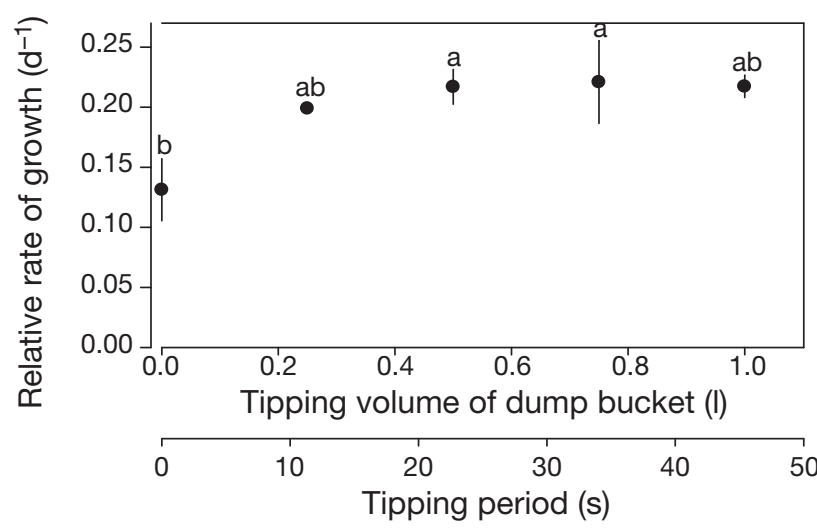

Fig. 3. Ulva pertusa. Effect of magnitude and period of wave surge on relative growth rates $\mathrm{d}^{-1}$ (in $\mathrm{g}$ wet weight per day) of specimens maintained in outdoor tanks at the same bulk flow rate $\left(2.24 \mathrm{~mm} \mathrm{~s}^{-1}\right)$. Symbols represent mean $\pm 1 \mathrm{SE}(\mathrm{n}=2$ to 3 ). One-way ANOVA: $F=4.4, \mathrm{p}=0.037, \mathrm{n}=2$ to 3 . Bars labelled with the same lower case letter do not differ significantly $(p>$ 0.05 ) according to Tukey's honestly significant difference test

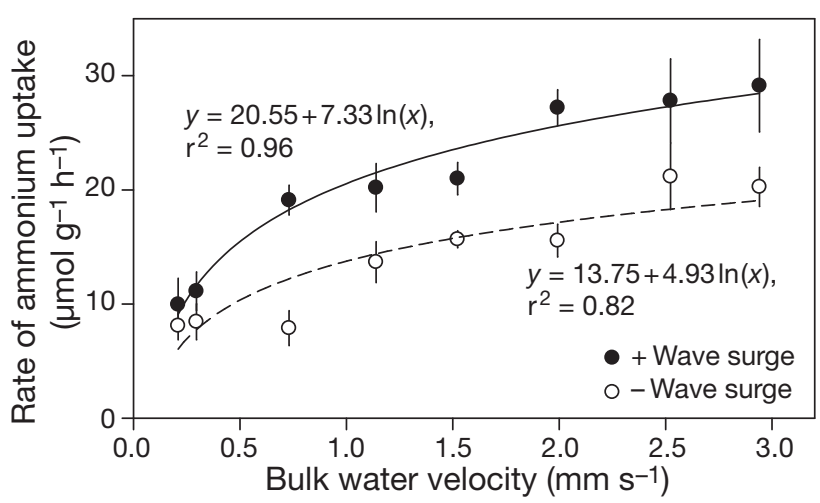

Fig. 4. Ulva pertusa. Effect of wave surge on uptake of ammonium (in $\mu$ mol per $g$ dry weight per hour) by specimens maintained at a range of bulk water velocities in indoor tanks. Symbols represent mean $\pm 1 \mathrm{SE}(\mathrm{n}=3)$. Regression lines were fitted by ordinary least squares

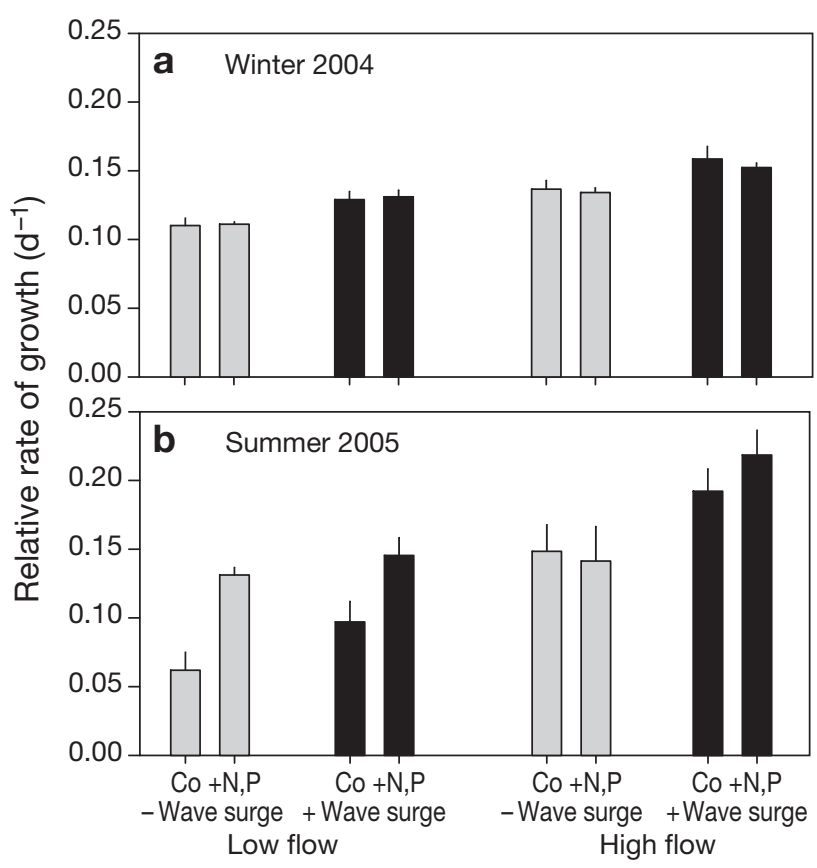

Fig. 5. Ulva pertusa. Effects of wave surge and nutrient (10 $\mu \mathrm{M}$ ammonium and $1 \mu \mathrm{M}$ phosphate) addition on relative growth of specimens maintained in outdoor tanks during: (a) winter 2004 and (b) summer 2005. Low and high bulk flow rates were 0.21 and $4.06 \mathrm{~mm} \mathrm{~s}^{-1}$, respectively. Co: control (no added nutrients) $+\mathrm{N}, \mathrm{P}$ : nutrient addition treatment. Bars represent mean $\pm 1 \mathrm{SE}(n=3)$. See 'Results' for statistics

nitrogen and phosphorus had a negligible effect on the growth rate of Ulva pertusa, while both wave surge and bulk flow rate had small positive effects (Fig. 5a). The overall range in relative growth rates across treatments was comparatively small (averages varied from 0.11 to $0.16 \mathrm{~d}^{-1}$, a 1.4 -fold range). A 3-way ANOVA found significant effects of wave surge $(F=27.0$, p < $0.0001)$ and bulk flow rate $(F=41.5, \mathrm{p}<0.0001)$, but not nutrients $(F=0.16, \mathrm{p}=0.69)$, and none of the interaction terms were significant $(F \leq 0.52, \mathrm{p} \geq 0.48)$. However, in summer, when ambient nutrient levels were comparatively low, results were quite different (Fig. 5b). At low bulk flow rates $\left(0.21 \mathrm{~mm} \mathrm{~s}^{-1}\right)$, the addition of nutrients had a clear positive effect on the rate of growth of $U$. pertusa, but the further addition of wave surge had little effect on growth (compare the second and fourth bars in Fig. 5b). In the high-flow (4.06 $\mathrm{mm} \mathrm{s}^{-1}$ ) treatments, overall growth rates were higher, but the addition of nutrients had little effect, and the effect of wave surge in the presence of nutrients was larger. The overall range in relative growth rates across treatments was much greater than in the winter experiment (averages varied from 0.06 to $0.22 \mathrm{~d}^{-1}$, a 3.5 -fold range, compared with a 1.4-fold range in winter). For the summer data, a 3-way ANOVA found significant effects of wave surge $(F=$ $13.2, \mathrm{p}=0.001)$, nutrients $(F=8.6, \mathrm{p}=0.007)$ and bulk 
flow rate $(F=32.4, \mathrm{p}<0.0001)$. The nutrient $\times$ bulk flow rate interaction was marginally significant $(F=4.51$, $\mathrm{p}=0.044)$, but none of the other interaction terms were significant $(F \leq 2.27, \mathrm{p} \geq 0.14)$.

\section{DISCUSSION}

Wave surge increased the relative rate of growth in wet mass of Ulva pertusa up to 1.6-fold (Fig. 2). At bulk flow velocities less than $\sim 2 \mathrm{~mm} \mathrm{~s}^{-1}$, the major effect of wave surge on growth appeared to be the increased provision of nitrogen and/or phosphorus to the surface of the seaweed. Several lines of evidence support this conclusion: (1) wave surge increased the rate of ammonium uptake by an average of 1.5 -fold across the 0.2 to $2.9 \mathrm{~mm} \mathrm{~s}^{-1}$ range of bulk flow velocities tested (Fig. 4); (2) wave surge had little effect on growth during winter, when ambient nutrient concentrations were high and light or temperature may have been limiting (Fig. 5a); and (3) wave surge had little additional effect over and above nutrient additions at low bulk flow rates in summer, when nutrients were likely limiting (Fig. 5b). We assume that wave surge: (1) reduces the thickness of the concentration boundary layer and/or (2) prevents the seaweed from conforming to flow and creating zones of stagnant water (Gaylord et al. 1994).

At bulk flow velocities greater than $\sim 2 \mathrm{~mm} \mathrm{~s}^{-1}$, wave surge still increased the rate of growth in wet mass (Figs. 2 \& 5), but it did not do so by enhancing access to nutrients. Nutrient addition had no effect on growth in the high bulk flow rate $\left(4.06 \mathrm{~mm} \mathrm{~s}^{-1}\right)$ treatments (Fig. 5), suggesting that nutrients do not limit growth at these bulk flow rates, regardless of wave surge. The non-nutrient effect of wave surge on growth, which dominated the effect of wave surge at higher bulk flow rates and was secondary to nutrients at low bulk flow rates, was indicated by the following: (1) at both low and high bulk flow rates, there was a small but consistent effect of wave surge in winter, when nutrient additions had no effect (Fig. 5a), and (2) in summer, there was a small but consistent effect of wave surge at high bulk flow rates, even though nutrient addition had no effect in the high-flow, no-wave surge treatment (Fig. $5 b)$. We speculate that this additional effect of wave surge may be due to: (1) increasing the supply of something other than nitrogen or phosphorus, e.g. carbon (Parker 1981, Raven 1984), or a micronutrient such as iron or zinc (Cooke et al. 2004), and/or (2) keeping the seaweed surface free of inhibitory excretory products (Gonen et al. 1995), fouling organisms, or particulate matter. Wave surge could also decrease the overall energy cost of growth by increasing the rate of uptake of carbon dioxide versus bicarbonate, as the former occurs by diffusion and the latter requires active transport (Cornelisen et al. 2007).

At the single bulk flow rate of $2.24 \mathrm{~mm} \mathrm{~s}^{-1}$, it made little difference to growth whether wave surge was small and frequent or large and infrequent (Fig. 3). This suggests that either infrequent dumps were still frequent enough to provide Ulva pertusa with access to saturating levels of nutrients and/or removal of inhibitory substances, or that the lesser effect of small dumps on concentration boundary layer thickness was offset by their higher frequency.

We observed a 4.9-fold increase in the rate of ammonium uptake as water motion increased from $0.18 \mathrm{~mm}$ $\mathrm{s}^{-1}$ without wave surge to $2.53 \mathrm{~mm} \mathrm{~s}^{-1}$ with wave surge. The range would obviously be greater if we could have compared the maximum rate of uptake with that occurring at zero water motion (not measured). Published values for increases in rates of ammonium uptake with water motion are 1.8-fold for Gracilaria gracilis with 0 to 500 oscillations $\mathrm{min}^{-1}$ (Smit 2002), up to 3.1-fold for Ulva lactuca with 0 to $150 \mathrm{~mm} \mathrm{~s}^{-1}$ (Parker 1981), up to 6 -fold for G. tikvahiae with 0 to $225 \mathrm{~mm} \mathrm{~s}^{-1}$ (Parker 1982), and 6.7-fold for Macrocystis pyrifera at 0 to $50 \mathrm{~mm} \mathrm{~s}^{-1}$ (Wheeler 1982), with comparable values for M. integrifolia at 0 to $160 \mathrm{~mm} \mathrm{~s}^{-1}$ (Hurd et al. 1996). Consequently, the enhancement in rates of ammonium uptake that we achieved through the addition of wave surge to low bulk flow rates was comparable to or exceeded the degree of enhancement achieved by others using much higher bulk flow rates, but without the addition of wave surge.

Our results have clear implications for those maintaining seaweeds in tanks for the purposes of stripping nutrients from wastewater or providing food for animals such as abalone (e.g. Shpigel et al. 1993, Troell et al. 1999, Neori et al. 2004), and thus support the advocacy of wave surge for such purposes by W. H. Adey and others (e.g. Adey \& Hackney 1989, Craggs et al. 1996, Adey \& Loveland 1998). At the low bulk flow rate of $1 \mathrm{~mm} \mathrm{~s}^{-1}$, the addition of a dump bucket to generate wave surge increased the relative rate of growth of Ulva pertusa by an amount that would have required a 9-fold increase in bulk water flow to achieve without wave surge (Fig. 2). It would be interesting to compare the effectiveness of dump buckets with other methods used to increase water movement in production or wastewater facilities (e.g. aeration; Shpigel et al. 1993, Troell et al. 1999, Neori et al. 2004).

It is currently unknown what factor(s) limit growth of New Zealand seaweeds. In general, the lowest tissue nitrogen content of temperate seaweeds (which is below the critical level required for maximum growth rate) coincides with the lowest concentrations of seawater inorganic nitrogen in summer (Hanisak 1983). Other nutrients that can limit seaweed growth include 
phosphorus (Wheeler \& Björnsäter 1992) and iron (Matsunaga et al. 1994). However, the available evidence suggests that iron does not limit growth at our site (Cooke et al. 2004) and the seawater inorganic molar $\mathrm{N}: \mathrm{P}$ ratio is sufficiently low, ranging from 4.1 in September to 7.5 in June (B. Dobson unpubl. data), suggesting that phosphorus is less likely to limit seaweed growth than nitrogen. Consequently, in nature, the benefit of wave surge is likely to be greatest during the summer, when nutrient levels are low and the water column is frequently calm and stratified (Fogg \& Thake 1987). During the winter, high background nutrient levels and light- or temperature-limitation may make the additional provision of nutrients by wave surge superfluous.

Our experiments were run at relatively low bulk flow rates, as may occur in environments such as tidepools, the interior of dense kelp forests and sheltered estuaries at slack water (Wheeler 1988, Koch 1993, 1994, Pearson et al. 1998), and demonstrate how the lack of mixing in such habitats can constrain seaweed growth. It remains to be seen whether wave surge also increases growth rates at higher bulk flow rates. In some finely structured seaweeds, a zone of stagnant water can be maintained in between thalli even in rapidly flowing water (Gaylord et al. 1994). Intermittent wave surge may act to remove such dead spots of water by preventing the seaweed from conforming to constant flow.

Acknowledgements. We thank B. Dobson for nutrient data, J. Evans for solar radiation and seawater temperature data, and P. Brown and L. Wilkes for helping with the experiments. Ulva pertusa was identified by C. Maggs and L. McIvor. We are grateful to the referees for their thoughtful and constructive comments.

\section{LITERATURE CITED}

Adey WH, Hackney JM (1989) The composition and production of tropical marine algal turfs in laboratory and field experiments. In: Adey WH, Farrier DF (eds) The biology, ecology and mariculture of Mithrax spinosissimus, utilizing cultured algal turfs. Mariculture Institute, Los Angeles, CA, p 1-80

Adey WH, Loveland K (1998) Dynamic aquaria: building living ecosystems, 2nd edn. Academic Press, San Diego, CA

Carpenter RC, Hackney JM, Adey WH (1991) Measurements of primary productivity and nitrogenase activity of coral reef algae in a chamber incorporating oscillatory flow. Limnol Oceanogr 36:40-49

Cochran WG (1951) Testing a linear relation among variances. Biometrics 7:17-32

Cooke RRM, Hurd CL, Lord JM, Peake BM, Raven JA, Rees TAV (2004) Iron and zinc content of Hormosira banksii in New Zealand. N Z J Mar Freshw Res 38:73-85

Cornelisen CD, Wing SR, Clark KL, Bowman MH, Frew RD, Hurd CL (2007) Patterns in the $\delta^{13} \mathrm{C}$ and $\delta^{15} \mathrm{~N}$ signature of Ulva pertusa: interaction between physical gradients and nutrient source pools. Limnol Oceanogr 52:820-832

Craggs RJ, Adey WH, Jenson KR, St John MS, Green FB, Oswald WJ (1996) Phosphorus removal from wastewater using an algal turf scrubber. Water Sci Technol 33: 191-198

Fogg GE, Thake B (1987) Algal cultures and phytoplankton ecology, 3rd edn. University of Wisconsin Press, Madison

Fujita RM, Goldman JC (1985) Nutrient flux and growth of the red alga Gracilaria tikvahiae McLachlan (Rhodophyta). Bot Mar 28:265-268

> Gaylord B, Blanchette CA, Denny MW (1994) Mechanical consequences of size in wave-swept algae. Ecol Monogr 64:287-313

> Gonen Y, Kimmel E, Friedlander M (1995) Diffusion boundary layer transport in Gracilaria conferta (Rhodophyta). J Phycol 31:768-773

Hanisak MD (1983) The nitrogen relationships of marine macroalgae. In: Carpenter EJ, Capone DG (eds) Nitrogen in the marine environment. Academic Press, New York, p 699-730

Hurd CL (2000) Water motion, marine macroalgal physiology, and production. J Phycol 36:453-472

> Hurd CL, Harrison PJ, Druehl LD (1996) Effect of seawater velocity on inorganic nitrogen uptake by morphologically distinct forms of Macrocystis integrifolia from wavesheltered and exposed sites. Mar Biol 126:205-214

> Koch EW (1993) The effect of water flow on photosynthetic processes of the alga Ulva lactuca L. Hydrobiologia 260/261:457-462

Koch EW (1994) Hydrodynamics, diffusion-boundary layers and photosynthesis of the seagrasses Thalassia testudinum and Cymodocea nodosa. Mar Biol 118:767-776

Koroleff F (1983a) Determination of ammonia. In: Grasshoff K, Ehrhardt M, Kremling K (eds) Methods of seawater analysis, 2nd edn. Verlag Chemie, Weinheim, p 150-157

Koroleff F (1983b) Determination of phosphorus. In: Grasshoff K, Ehrhardt M, Kremling K (eds) Methods of seawater analysis, 2nd edn. Verlag Chemie, Weinheim, p 125-139

> Larned ST, Atkinson MJ (1997) Effects of water velocity on $\mathrm{NH}_{4}$ and $\mathrm{PO}_{4}$ uptake and nutrient-limited growth in the macroalga Dictyosphaeria cavernosa. Mar Ecol Prog Ser 157:295-302

> Leigh EG Jr, Paine RT, Quinn JF, Suchanek TH (1987) Wave energy and intertidal productivity. Proc Natl Acad Sci USA 84:1314-1318

> Littler MM, Arnold KE (1982) Primary productivity of marine macroalgal functional-form groups from southwestern North America. J Phycol 18:307-311

Lobban CS, Harrison PJ (1997) Seaweed ecology and physiology. Cambridge University Press, Cambridge

Luckett C, Adey WH, Morrissey J, Spoon DM (1996) Coral reef mesocosms and microcosms-successes, problems, and the future of laboratory models. Ecol Eng 6:57-72

Matsunaga K, Suzuki Y, Kuma K, Kudo I (1994) Diffusion of $\mathrm{Fe}(\mathrm{II})$ from an iron propagation cage and its effect on tissue iron and pigments of macroalgae on the cage. J Appl Phycol 6:397-403

Neori A, Chopin T, Troell M, Buschmann AH and others (2004) Integrated aquaculture: rationale, evolution and state of the art emphasizing seaweed biofiltration in modern mariculture. Aquaculture 231:361-391

Nielsen SL, Sand-Jensen K (1990) Allometric scaling of maximal photosynthetic growth rate to surface/volume ratio. Limnol Oceanogr 35:177-181

Nishihara GN, Ackerman JD (2007) On the determination of mass transfer in a concentration boundary layer. Limnol Oceanogr Methods 5:88-96 
Parker HS (1981) Influence of relative water motion on the growth, ammonium uptake and carbon and nitrogen composition of Ulva lactuca (Chlorophyta). Mar Biol 63: 309-318

Parker HS (1982) Effects of simulated current on the growth rate and nitrogen metabolism of Gracilaria tikvahiae (Rhodophyta). Mar Biol 69:137-145

Parsons TR, Maita Y, Lalli CM (1984) A manual of chemical and biological methods for seawater analysis. Pergamon Press, Oxford

Pearson GA, Serrão EA, Brawley SH (1998) Control of gamete release in fucoid algae: sensing hydrodynamic conditions via carbon acquisition. Ecology 79:1725-1739

Raffaelli DG, Raven JA, Poole LJ (1998) Ecological impact of green macroalgal blooms. Oceanogr Mar Biol Annu Rev 36:97-125

Raven JA (1984) Energetics and transport in aquatic plants. Alan R. Liss, New York

Rosenberg G, Ramus J (1984) Uptake of inorganic nitrogen and seaweed surface area:volume ratios. Aquat Bot 19:65-72

Sanford LP, Crawford SM (2000) Mass transfer versus kinetic control of uptake across solid-water boundaries. Limnol Oceanogr 45:1180-1186

Shpigel M, Neori A, Popper DM, Gordin H (1993) A proposed model for 'environmentally clean' land-based culture of fish, bivalves and seaweeds. Aquaculture 117:115-128

Editorial responsibility: Kedong Yin, Brisbane, Queensland, Australia
Smit AJ (2002) Nitrogen uptake by Gracilaria gracilis (Rhodophyta): adaptations to a temporally variable nitrogen environment. Bot Mar 45:196-209

Stephenson TA, Stephenson A (1972) Life between tidemarks on rocky shores. W. H. Freeman and Company, San Francisco, CA

> Thomas FIM, Cornelisen CD (2003) Ammonium uptake by seagrass communities: effects of oscillatory versus unidirectional flow. Mar Ecol Prog Ser 247:51-57

Troell M, Rönnbäck P, Halling C, Kautsky N, Buschmann A (1999) Ecological engineering in aquaculture: use of seaweeds for removing nutrients from intensive mariculture. J Appl Phycol 11:89-97

Wheeler WN (1982) Nitrogen nutrition of Macrocystis. In: Srivastava LM (ed) Synthetic and degradative processes in marine macrophytes. Walter de Gruyter, Berlin, p 121-137

Wheeler WN (1988) Algal productivity and hydrodynamicsa synthesis. Prog Phycol Res 6:23-58

Wheeler PA, Björnsäter BR (1992) Seasonal fluctuations in tissue nitrogen, phosphorus, and N:P for five macroalgal species common to the Pacific Northwest coast. J Phycol 28:1-6

- Williams SL, Carpenter RC (1998) Effects of unidirectional and oscillatory water flow on nitrogen fixation (acetylene reduction) in coral reef algal turfs, Kaneohe Bay, Hawaii. J Exp Mar Biol Ecol 226:293-316

Submitted: November 24, 2007; Accepted: July 1, 2008

Proofs received from author(s): July 28, 2008 